\title{
Characterization of New Rice Lines Adapted to Medium Altitude Ecological Conditions in Burundi
}

\author{
BANDUSHUBWENGE Denis ${ }^{* 1} \&$ KWIZERA Chantal ${ }^{2}$ \\ ${ }^{1}$ University of Burundi, Faculty of Agriculture and Bio Engineering, Department of vegetal productions \\ Sciences, B.P 2940 Bujumbura, Burundi \\ ${ }^{2}$ University of Burundi, Faculty of Agriculture and Bio Engineering, Department of Environment \\ Sciences and Technologies, B.P 2940 Bujumbura, Burundi
}

\begin{abstract}
Rice is a luxyry food, cereal that constitutes a major source of calories for the urban and rural population. It is the second largest crop grown worldwide. In Burundi country, rice demand has been increasing more rapidly in both urban and sub-urban areas due to its use in alcohol and oil fabrication, marketing for houselhold economic income, and cattle feeding. Unfortunately rice production are limited due to population growth, coupled with its cultivation almost in lower altitude regions only. An experiment on caracterisation of new rice lines for development of high yielding genotypes with desirable agronomic traits was carried out to assess the most adapted lines which could be recommanded to farmers in the region. The experiment was laid out in randomized complete block design with three replications. It has considered 10 rice lignes (V3, V7, V8, V13, V14, V16, V18, V22, V34, V35), planted on 8 ha area, divided in single plots of $8 \mathrm{~m}^{2}$ each with $20 \mathrm{X} 20 \mathrm{~cm}$ for spacing. Based on statistic analysis, results of the study showed line V34 as the most adapted variety with significance difference comparatively to other lines. It showed improved growth parameters as plant height, panicles exsertion and panicles length. Moreover, this line V34 has recorded enhenced yield with $p<0.05$ as compared to others. Likewise, improved pinicles number and thousand grains weight were observed for this line V34. The study highlighted line V34 as the most adapted line that could be recommanded to the people of the region.
\end{abstract}

Keys words : Rice crop lines, Medium altitude regions, Growth parameters, yield attributes.

\section{INTRODUCTION}

Rice is an important cereal, as it is the second largest crop grown worldwide ${ }^{[1]}$. It affects a significant proportion of the world's smallholders and urban consumers. Rice is a luxyry food, cereal that constitutes a major source of calories for the urban and rural population. Its bran is an essential part of whole grains which is produced as byproduct of milling in producing refined grains ${ }^{[2,3]}$. It has high content of dietary fiber, essential fatty acids and other vital amounts of protein, starch, dietary minerals and vitamins. Furthermore, it has a wide range of health benefits with the presence of vitamin E, antioxidants, vitamin B and essential fatty acids have been asserted in rice bran. It is a great source of phytosterols which helps to control blood sugar, cholesterol metabolism and prostate health. Naturally, it is gluten free, lactose free and hypoallergenic which makes it tolerable health product for various tastes ${ }^{[4]}$. Overall, Rice is a staple food for more than half of the world's seven billion people, it is of crucial importance in providing food security for an exponentially growing population. Foregoing research confirmed that rice consumption is growing faster than that of any major food ${ }^{[2,3]}$, while the world population is expected to grow susbtantially as the population is currently growing at the rate of 3 to $4 \%$ per annum. Moreover, rice is the most rapidly growing food commodity in sub-saharan Africa. It has become a commodity of strategic significance and the fastest-growing food source in Africa, such that its availability and price are now a mojar determinant of the welfare of poorest segment of consumers who are the least food-secure consummers in Africa ${ }^{[5]}$. Whence increase in rice production is needed to meet future population demand. Burundi also is not spared with a growth of $3.2 \%$ in $2018{ }^{[6]}$. In this country, rice has emerged as an important food. Its demand has been increasing more rapidly in both urban and sub-urban areas of the country. This rapid increase in rice demand is largely due to rapid population growth, its use in marketing for houselhold economic income, and its contribution in food security. Moreover, rice grains in the country are used 
for alcohol and oil fabrication, while flour and straw are used for cattle feeding. Rice is a major crop in the country, unfortunately rice production are limited due to population growth, coupled with its cultivation almost in lower altitude regions only, whence yield increase is a necessity to obtain rice self-sufficient and meet the future demand. An experiment on caracterisation of new rice lines for development of high yielding genotypes with desirable agronomic traits was carried out to assess the most adapted lines which could be recommanded to farmers in the region.

\section{MATERIALS AND METHODS}

\subsection{Site Description and experiment design}

The experimentation site was located in Giheta commune of Gitega province at Ndebe, a center of kirimiro region, with $1492 \mathrm{~m}$ of altitude, characterized by annuel precipitation varying between 1200 and $1400 \mathrm{~mm}$ and a mean temperature ranged between 20.5 and $23{ }^{\circ} \mathrm{C}$. The soil texture was sandy silt clay with a pH of 5.9. The experiment was laid out in randomized complete block design with three replications. It has considered 10 rice lignes (V3, V7, V8, V13, V14, V16, V18, V22, V34, V35), planted on 8 ha area, divided in single plots of $8 \mathrm{~m}^{2}$ each with $20 \times 20 \mathrm{~cm}$ for spacing. These 8 ha were in two parts: 5 ha in marsh and 3 ha on a hill. During the experiment, fertilizers have been applied following the recommanded rate with N-P-K (30-30-30) formula. Later, $100 \mathrm{~kg}$ of urea has been applied twices as cover manure. The first part (35kg/ha) was applied two weeks after plantation, while the other part $(65 \mathrm{~kg} / \mathrm{ha})$ was applied at panicles appearance time.

\subsection{Data sampling}

During growth, plant heigh, panicles exsertion and panicle length were recorded. At physiological maturity, data on grain yield and its component were determined after oven-drying at $70^{\circ} \mathrm{C}$ to constant weight.

\subsection{Statistical analysis}

Data statistical analysis was done through STATITCT and advanced Excel. Comparisons between lines were conducted using Student-Newman-Keuls test at 5\%, while Excel was used for figures and tables.

\section{RESULTS}

\subsection{Plant height (PH) assessment}

Rice crop height is an important agronomic trait linked to plant type and yield potential. It is a major phenotypic morphology parameter that can be used not only as an indicator of overall plant growth vigor, but a parameter to estimate other crop traits ${ }^{[4,5]}$. In this study, plant height has been tested and analysed as can be seen in Figure1.

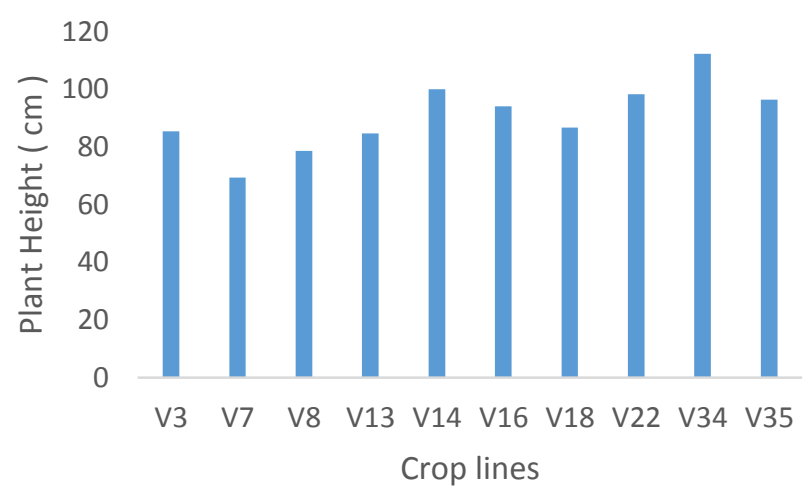

Figure 1. Plant height (PH) analysis

The highest PH of $112.33 \mathrm{~cm}$ was recorded for V34, and significantly differed to others with a probability value $\mathrm{p}<0.05$. It was followed by V14 with $100 \mathrm{~cm}$, a variety which did not shows significant difference from V22 $(98.33 \mathrm{~cm})$, V35 $(96.33 \mathrm{~cm})$ and V16 $(94.00 \mathrm{~cm})$. The shortest plant was recorded for V7 with $69.33 \mathrm{~cm}$.

\subsection{Panicles lenght (PL) analysis}

From an agronomic perspective, panicle length is a major determinant of grains number per panicle ${ }^{[7,8]}$. It is a key trait for genetic factor identification as revealed by Liu et al. (2010) and Kato et al. $(2009)^{[9,10]}$. Panicle length determines the number of grains 
that panicle can hold, and consequently rice yield projection. It is one of the most important traits assessed in yield-related research $^{[11]}$. In this study, data on panicle length are as follows (Table 1).

Table 1. Panicles length assessment

\begin{tabular}{ll}
\hline Crop Lines & Panicles length analysis \\
\hline V34 & $24.00 \mathrm{a}$ \\
V16 & $23.67 \mathrm{a}$ \\
V14 & $22.33 \mathrm{ab}$ \\
V7 & $21.67 \mathrm{ab}$ \\
V35 & $20.00 \mathrm{bc}$ \\
V8 & $19.67 \mathrm{bc}$ \\
V13 & $19.00 \mathrm{bc}$ \\
V22 & $18.67 \mathrm{bc}$ \\
V18 & $17.33 \mathrm{c}$ \\
V3 & $16.33 \mathrm{c}$ \\
\hline
\end{tabular}

Through this table 1, Significant difference was observed between lines with V34 the first adapted line than others. Specifically, highest PL was observed for line V34 with $24 \mathrm{~cm}$, followed by lines V16 of $23.67 \mathrm{~cm}$ and minimum for V3 with $16.67 \mathrm{~cm}$. Statistically, there was no significance difference between V34 and V16, but both significantly differed to V3 with probability value $\mathrm{p}<0.05$.

\subsection{Panicles number $(P N)$ analysis}

Panicle is closely associated with yield, a key indicator of rice production due to it directly regulates the grain number ${ }^{[12]}$. Relate results in the present study are summed up in the figure 2

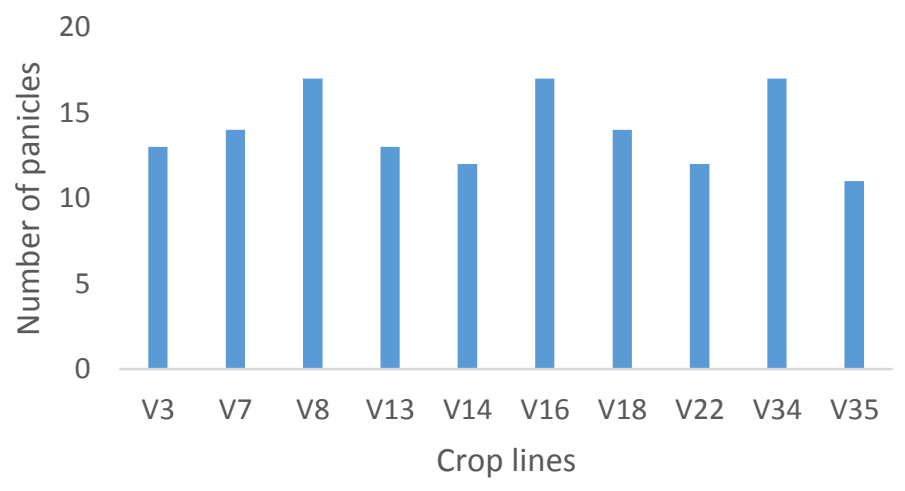

Figure 2. Panicles number (PN) analysis

Regarding panicles number, there was no signifance difference between lines. The maximum PN of 17 panicles was observed for V34 line. The same value was observed for both lines V16 and V8. They were followed by V7 and V18 which both showed an average of 14 panicles. The munimum value was observed for line V35 with 11 panicles.

\subsection{Panicle exsertion (PE) analysis}

Panicle exsertion is related to many other traits in rice as demonstrated by foregoing researchers ${ }^{[13]}$. It was reported that incomplete panicle exsertion is one of the symptoms which damages grain yield and raises disease incidence ${ }^{[14]}$, whence panicle exsertion is a better indicator under field conditions. For the present study, outcomes on panicle exsertion were displayed in table 2. 
Table 2. Panicle exsertion analysis

\begin{tabular}{ll}
\hline Crop Lines & Panicles exsertion analysis \\
\hline V7 & $7.00 \mathrm{a}$ \\
V3 & $5.67 \mathrm{~b}$ \\
V18 & $5.00 \mathrm{~b}$ \\
V16 & $5.00 \mathrm{~b}$ \\
V35 & $3.00 \mathrm{c}$ \\
V8 & $2.33 \mathrm{~cd}$ \\
V13 & $2.33 \mathrm{~cd}$ \\
V22 & $1.00 \mathrm{~d}$ \\
V14 & $1.00 \mathrm{~d}$ \\
V34 & $1.00 \mathrm{~d}$ \\
\hline
\end{tabular}

Panicle exsertion analysis showed significance difference between lines. The better value of 1 was observed for lines V34, V22, and V14. These lines did not significantly deffered to V13 and V8, lines with the second highest value of 2.33 for both, but significantly differed to others with $\mathrm{p}<0.05$. Moreover, from table 2 , the worst value of 7 was recorded for lines V7.

\subsection{Weight of Thousand grains (WTG) and yield}

Thousand grain weight represents the average value of individual grain weight which depends on position within the ear and on positon within the spikelet ${ }^{[15]}$. Sharma (2009) highlited that wide variability which has implications for commercial value exists in individual grain weight. Furthermore, grain yield is an important parameter for evaluating the potential of new rice cultivars as reported by Ferrante et al. (2017) ${ }^{[16]}$. It is a key trait that effects grain cultivation, management, and subsequent yield ${ }^{[17,18]}$, whence assessment of thousand grains weight is a major focus especially in Burundi where rice is a marketing key tools nowadays. Relate outcomes were shown in figure 3 and 4.

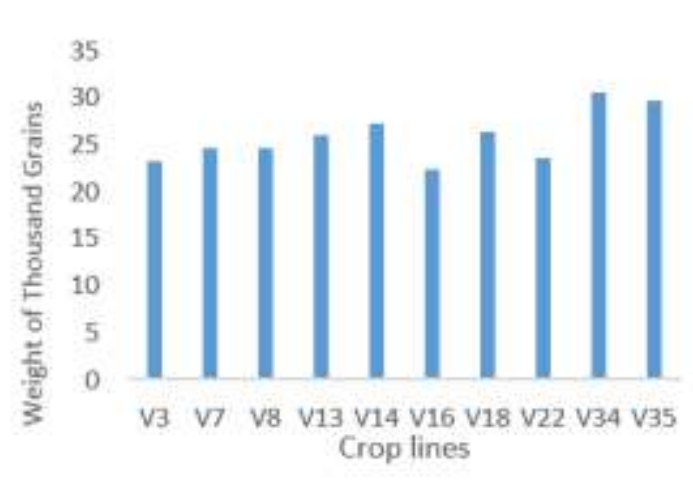

Figure 3. Weight of Thousand grains Analysis

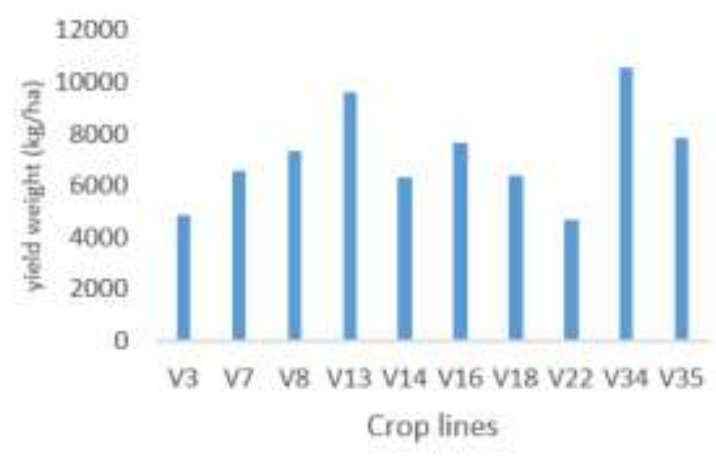

Figure 4. Yield assessment

Considering figure 3, data shows line 34 as the most adapted in the region. It recorded the optimum TWG of $30.67 \mathrm{~g}$ and significanly differed to others except V35 which was the following with $29.67 \mathrm{~g}$. However line V16 recorded the minimum value with $22.33 \mathrm{~g}$. The same trend was observed for figure 4 where the highest yield was observed for line V34 of $10578.67 \mathrm{~kg} / \mathrm{ha}$. This line differed to others with probability value $\mathrm{p}<0.05$. The minimum was recorded for line V22 with $4704 \mathrm{~kg} / \mathrm{ha}$.

\section{DISCUSSION}

Results of the study showed line V34 as the most adapted variety than others. It has shown improved growth parameters as plant height, panicle exsertion and panicles length. Moreover, this line V34 has recorded enhanced yield and its attributes like pinicles number, thousand grains weight and yield. The improvement of crop height was due to cell elongation rate since cell division is restricted to a small portion of the shoots and roots as revealed by Miyoshi Haruta and Michael R. Sussman ${ }^{[19]}$. It will lead to more nutritious crop yield due to that investment in height improves access to light leading to improved photosynthetic activities ${ }^{[20]}$, whence synthesis of more nutrients in plant. Althought grains number parameter was not assessed in this study, it could be positively affected due to improved panicle exsertion which is connected to the culm and panicle, parts controlling the transport of 
water and nutrients from the leaves and stems to grains and ultimately affecting grain filling as highted by Ma et al. (2002); da Cruz et al. (2008) and Liu et al. (2008) ${ }^{[21,22,23]}$. The improvement of yield and other tested parameters observed for V34 was due to the condicive environment for this line through which the plant could assimilate adequate nutrients for its growth and developpment.

\section{CONCLUSION}

Results of the study showed line V34 as the most adapted variety in the region. It showed improved growth parameters as plant height, panicles exsertion and panicles length. Moreover, this line V34 has recorded enhenced yield and its attributes like pinicles number, thousand grains weight and yield. Furthermore, based on foregoing research, more nutritious yield could be expected from line V34, whence enhanced food security as well as farmers livelihoods. The study highlighted line V34 as the most adapted line that could be recommanded to the people of the region.

\section{REFERENCES}

[1] Muthayya, S., Sugimoto, J. D., Montgomery, S., \& Maberly, G. F. (2014). An overview of global rice production, supply, trade and consumption. Annals of the New York Academy of Science, 1324, 7-14.

[2] Ogunbaye S.A., Oja D.K., Guei RG, Oyelakin O, Sanni K.A. (2005). Phylogenetic diversity and relationship among forty rice accessions using Morphological and RAPDs techniques. African Journal of Biotechnol. Vol 4: 1234-1244

[3] Seck PA, Toure AA, Coulibaly JY, Diagne A, Wopereis MCS (2013). African's rice economy before and after 2008 rice crisis pp. 24-34. In : Wopereis MCS, Jonson DE, Ahmadi N, Tollens E, Jalloh A(Eds), Realizing African's rice promise. CABI International ( UK) and Africa Rice ( Benin) 480 pp

[4] https://www.healthbenefitstimes.com/rice-bran/.Retreaved on the 13rd January 2021

[5] Nownze KF, Mohapatra S, Kmawa P, Keya S, Bruce-Oliver S (2006). Rice development in sub-Saharan African Journal of Science Food Agric. 86 : 675-677.

[6 ]population growth in burundi Retreaved on the 12nd 2021

[7] Cheng, F., Zhang, Q., Zhu, H., Zhao, N., Wang, F., Chen, K., Zhang, G., 2007. The difference in amylose content within a panicle as affected by the panicle morphology of rice cultivars. Journal of CerealScience 46, 49-57

[8] Kobayasi, K., Horie, Y., Imaki, T., 2002. Relationship between apical dome diameter at panicle initiation and the size of panicle components in rice grown under different nitrogen conditions during the Vegetative Stage. Plant Production Science 5 (1), 3-7

[9] Liu, G., Mei, H., Liu, H., Yu, X., Zou, G., Luo, L., 2010. Sensitivities of rice grain yield and other panicle characters to late-stage drought stress revealed by phenotypic correlation and QTL analysis. Molecular Breeding 25, 603-613 [10] Kato, Y., Nemoto, K., Yamagishi, J., 2009. QTL analysis of panicle morphology response to irrigation regime in aerobic rice culture. Field Crops Research 114,295-303

[11] Xiao, J., Li, J., Grandillo, S., Ahn, S., Yuan, L., Tanksley, S., McCouch, S., 1998.

Identification of trait-improving quantitative trait loci alleles from a wild rice relative, Oryza rufipogon. Genetics 150, 899-909

[12]keda, Y. Hirose, T. Takashi, Y. Shibata, T. Yamamura, T. Komura, K. Doi, M.Ashikari, M. Matsuoka, H. Kitano. Analysis of rice panicle traits and detection of QTLs using an image analyzing method. Breed. Sci., 60 (2010), pp. 55-64

[13] Hittalmani, S.; Shashidhar, H.E.; Bagali, P.; Huang, N.; Sidhu, J.S.; Singh, V.P. Khush, G.S. Molecular mapping of quantitative trait loci for plant growth, yield and yield related traits across three diverse locations in a doubled haploid rice population. Euphytica, v.125, p.207-214, 2002.

[14] Improvement of rice in Chile due to cold tolerance. In: meeting on rice improvement in the southern cone, Montevideo, 1991. Proceedings. Montevideo: IICA-Procisur, 1991. p.105-114 
[15] Sharma D. L., Shackley B. J, Amjad M., Zaicou-Kunesch C. M., D’Antuono M. F., and Anderson W. K. 2009. "Use of Grain Size Distribution Parameters to Explain Variation in Small Grain Screenings of Wheat in Multi-Environment Trials Involving New Cultivars." Crop \& Pasture Science

[16] Ferrante A, Cartelle J, Savin R, Slafer GA. Yield determination, interplay between major components and yield stability in a traditional and a contemporary wheat across a wide range of environments. Field Crop Res. 2017 ; 203 :114- 127

[17] Garcia GA, Serrago RA, Dreccer MF, Miralles DJ. Post-anthesis warm nights reduce grain weight in field-grown wheat and barley. Field Crop Res. 2016;195: 50 - 59

[18] Slafer GA, Savin R, Sadras VO. Coarse and fine regulation of wheat yield components in response to genotype and environment. Field Crop Res. 2014;157:71-83

[19] Miyoshi Haruta, Michael R. Sussman, in Current Topics in Developmental Biology, 2017. Protein Kinases in Development and Disease. Science Direct, journals and Books

[20] Daniel S. Falster and Mark Westoby. Plant height and evolutionary games. Department of Biological Sciences, Macquarie University, Sydney, NSW 2109, Australia

[21] Ma J, Zhou KD, Ma WB, Wang XD, Tian YH, Ming DF, Xu FY (2002) The characteristics of the tissues of the first internode and their relations to the grain-filling for the different panicle types of rice. Acta Agron Sinica 28:215-220

[22] Da Cruz RP, Milach SCK, Federizzi LC (2008) Inheritance of panicle exsertion in rice. Sci Agric 65:502-507

[23] Liu, J. G., Fritz, S., Van Wesenbeeck, C. F. A., Fuchs, M., You, L. Z., Obersteiner,M., \& Yang, H. (2008). A spatially explicit assessment of current and future hotspots of hunger in Sub-Saharan Africa in the context of global change. Global and Planetary Change, 64, 222-235. https://doi.org/10.1016/j.gloplacha.2008.09.007 